sequence - with respect to the spectrum of the so-formed solid and volatile products. As it has been shown, there is a clearcut difference between the reactive behaviour of alkaline earth metal and transition-metal carbonates: the decomposition of the former always leads to the corresponding metal oxide $\mathrm{MO}$, which in turn can be reversibly transformed into the carbonate. The degradation of the latter leads to transition metal oxides $\mathrm{MO}_{x}$ with varying oxygen stoichiometry and/or to elemental transition metals. The observation of different volatile carbon species gives evidence for the in situ formation of catalytically active transitionmetal compounds. This means also, that in reducing atmospheres these transition-metal species are in many cases active catalysts for the conversion of the volatile products $\mathrm{CO}_{2}$ and $\mathrm{CO}$ into reduced and, therefore, interesting carbon compounds, mainly $\mathrm{CH}_{4}$. The combination of alkaline earth metal carbonates with transition-metal carbonates allows not only to lower the decomposition temperatures drastically, but also to produce finely dispersed, catalytically active transitionmetal compounds on a selected support material. As example a combination of any transition-metal compound with simultaneously formed appropriate supports such as the well-established support materials $\mathrm{MgO}$ or $\mathrm{ZnO}$ can be thought of. The knowledge of the influences of experimental parameters such as temperature program, inert or reactive gas atmosphere, or even the type of energy impact onto kinetics and mechanism of the degradation of the initial carbonates allows the optimization of the solid products. Depending on the experimental conditions, in situ formation of catalysts can take place. Simultaneously, the evolved volatile species can be catalytically transformed during the degradation process of the initial carbonate. Therefore, the palette of volatile carbon compounds gives a hint for the catalytic potential of the system under investigation. The study of the reactivity of metal carbonates obviously leads into a multidisciplinary field, comprising aspects of heterogeneous solid-state chemistry, heterogeneous catalysis, thermochemistry, photochemistry, an 'interface' between inorganic and organic chemistry, and - last but not least - some more details on the most interesting reactive behaviour of $\mathrm{CO}_{2}$. These studies are also related to the research topic of chemical solar energy conversion, i.e. to convert radiation energy into useful chemical forms (see e.g. [20][21]). The results of these investigations elucidate the need of multidisciplinary approaches and concepts for the description and understanding of the initially underestimated complexity of the reactivity of metal carbonates.

The authors are indebted to the Bundesamt fiit Energiewirtschaft for financial support.

Received: July 31, 1991

[1] 'Römpps Chemie-Lexikon', 8th edn., Franckh' sche Verlagshandlung, Stuttgart, 1979, p. 563ff.
[2] 'Ullmanns Enzyklopädie der technischen Chemie', 4th edn., Verlag Chemie, Weinheim, 1979. Vol. 13, p. 497.

[3] C. Junge, Naturwissenschaften 1981, 68, 236.

[4] H. Oeschger, U. Siegenthaler, T. Wenk, in 'Primary Energy, Present State and Future Perspectives', Ed. K.O. Thielheim, Springer, BerlinHeidelberg-New York, 1982, p. $47 \mathrm{ff}$.

[5] H. Oeschger, Chimia 1989, 43, 331.

[6] P. Hug, Ph.D. Thesis, University of Zürich, 1991.

[7] R. Emmenegger, Ph.D. Thesis, University of Zürich, 1991.

[8] R.J. Reeder, in 'Carbonates, Mineralogy and Chemistry', Ed. R.J. Reeder, Mineralogical Society of America, 1983, p. 1.

[9] S.R. Kamhi, Acta Crystallogr. 1963, 16, 770.

[10] W.D. Carlson, in 'Carbonates, Mineralogy and Chemistry', Ed. R.J. Reeder, Mineralogical Society of America, 1983, p. 191.

[11] R.J.P. Williams, Philos. Trans. R. Soc. London, Ser. B 1984, 304, 411.

[12] S. Weiner, W. Traub, Philos. Trans. R. Soc. London Ser. B 1984, 304, 425.

[13] P. Westbroek, E.W. DeJong, P. Van der Wal, A.H. Borman, J.P.M. DeVrind, D. Kok, W.C. De Bruijn, S.B. Parker, Philos. Trans. R. Soc. London, Ser. B 1984, $304,435$.

[14] M. Maciejewski, A. Reller, Thermochim. Acta $1987,110,145$

[15] M. Maciejewski, A. Reller, Thermochim. Acta $1989,142,175$

[16] C. Padeste, Ph.D. thesis, University of Zürich, 1989.

[17] C. Padeste, A. Reller, H.R. Oswald, Mat. Res. Bull. 1990, 25, 1299.

[18] A. Reller, C. Padeste, P. Hug, Nature (London) $1987,329,527$

[19] R. Emmenegger, H.R. Oswald, A. Reller, Sol. Energy Mater., in press.

[20] R. Memming, Topics Curr. Chem. 1991,143,81.

[21] A. Henglein, Topics Curr. Chem. 1991, 143, 115.
Chimia 45 (1991) 266-268

(c) Schweiz. Chemiker-Verband; ISSN 0009-4293

\title{
Self-replicating Reverse Micelles
}

Pascale Angelica Bachmann'), Pier Luigi Luisi')*, and Jacques Lang²)

Abstract. Conditions are described, under which the hydrolysis of octyl octanoate (O-OA) takes place at the interface of reverse micelles formed by sodium octanoate (OA) in isooctane. Since the micelle-mediated hydrolysis affords fresh OA, which spontaneously assemble into new micelles, the reaction can be seen as a self-replicating process. The kinetics and the spectroscopy of this self-replication process are presented.

\section{Introduction}

Reverse micelles can be seen as small droplets of $\mathrm{H}_{2} \mathrm{O}$ (with a radius in the range of $10-100 \AA)$ which are stabilized in organic solvents by a layer of surfactant. Reverse micelles are usually monodisperse, and their physical properties depend primarily on the molar ratio of $\mathrm{H}_{2} \mathrm{O}$ to surfactant, usually defined as $w_{0}\left(w_{0}=\left[\mathrm{H}_{2} \mathrm{O}\right] /[\right.$ surfactant $\left.]\right)$ :e.g., the radius of the $\mathrm{H}_{2} \mathrm{O}$ pool depends almost linearly on $w_{0}[1-3]$. To an organic chemist, reverse micelles are also of interest as microreactors: a series of $\mathrm{H}_{2} \mathrm{O}$-soluble compounds can be solubilized in the $\mathrm{H}_{2} \mathrm{O}$ pool of the micelles, thus permitting reactions between hydrophilic compounds essentially in a bulk aprotic solvent [4][5].

Quite recently, a new type of a chemical reaction in reverse micelles has been proposed [6], one which brings to self-replication of the micelles themselves. The principle is the following: the reverse micelle hosts a reaction which yields the very surfactant which builds the micelle. The soproduced fresh surfactant accumulates at the micellar interface; however, the micelle cannot grow in size, since $\mathrm{H}_{2} \mathrm{O}$ is limiting. Actually, since $w_{0}$ decreases, the thermodynamic constraints impose formation of a

\footnotetext{
*Correspondence: Prof. P. L. Luisi

1) Institut für Polymere, ETH-Zentrum

Universitätstrasse 6, CH-8092 Zürich

2) Institut Charles Sadron (CRM-EAHP) CNRS

6 , rue Boussingault, F-67000 Strasbourg
} 
sequence - with respect to the spectrum of the so-formed solid and volatile products. As it has been shown, there is a clearcut difference between the reactive behaviour of alkaline earth metal and transition-metal carbonates: the decomposition of the former always leads to the corresponding metal oxide $\mathrm{MO}$, which in turn can be reversibly transformed into the carbonate. The degradation of the latter leads to transition metal oxides $\mathrm{MO}_{x}$ with varying oxygen stoichiometry and/or to elemental transition metals. The observation of different volatile carbon species gives evidence for the in situ formation of catalytically active transitionmetal compounds. This means also, that in reducing atmospheres these transition-metal species are in many cases active catalysts for the conversion of the volatile products $\mathrm{CO}_{2}$ and $\mathrm{CO}$ into reduced and, therefore, interesting carbon compounds, mainly $\mathrm{CH}_{4}$. The combination of alkaline earth metal carbonates with transition-metal carbonates allows not only to lower the decomposition temperatures drastically, but also to produce finely dispersed, catalytically active transitionmetal compounds on a selected support material. As example a combination of any transition-metal compound with simultaneously formed appropriate supports such as the well-established support materials $\mathrm{MgO}$ or $\mathrm{ZnO}$ can be thought of. The knowledge of the influences of experimental parameters such as temperature program, inert or reactive gas atmosphere, or even the type of energy impact onto kinetics and mechanism of the degradation of the initial carbonates allows the optimization of the solid products. Depending on the experimental conditions, in situ formation of catalysts can take place. Simultaneously, the evolved volatile species can be catalytically transformed during the degradation process of the initial carbonate. Therefore, the palette of volatile carbon compounds gives a hint for the catalytic potential of the system under investigation. The study of the reactivity of metal carbonates obviously leads into a multidisciplinary field, comprising aspects of heterogeneous solid-state chemistry, heterogeneous catalysis, thermochemistry, photochemistry, an 'interface' between inorganic and organic chemistry, and - last but not least - some more details on the most interesting reactive behaviour of $\mathrm{CO}_{2}$. These studies are also related to the research topic of chemical solar energy conversion, i.e. to convert radiation energy into useful chemical forms (see e.g. [20][21]). The results of these investigations elucidate the need of multidisciplinary approaches and concepts for the description and understanding of the initially underestimated complexity of the reactivity of metal carbonates.

The authors are indebted to the Bundesamt fiit Energiewirtschaft for financial support.

Received: July 31, 1991

[1] 'Römpps Chemie-Lexikon', 8th edn., Franckh' sche Verlagshandlung, Stuttgart, 1979, p. 563ff.
[2] 'Ullmanns Enzyklopädie der technischen Chemie', 4th edn., Verlag Chemie, Weinheim, 1979. Vol. 13, p. 497.

[3] C. Junge, Naturwissenschaften 1981, 68, 236.

[4] H. Oeschger, U. Siegenthaler, T. Wenk, in 'Primary Energy, Present State and Future Perspectives', Ed. K.O. Thielheim, Springer, BerlinHeidelberg-New York, 1982, p. $47 \mathrm{ff}$.

[5] H. Oeschger, Chimia 1989, 43, 331.

[6] P. Hug, Ph.D. Thesis, University of Zürich, 1991.

[7] R. Emmenegger, Ph.D. Thesis, University of Zürich, 1991.

[8] R.J. Reeder, in 'Carbonates, Mineralogy and Chemistry', Ed. R.J. Reeder, Mineralogical Society of America, 1983, p. 1.

[9] S.R. Kamhi, Acta Crystallogr. 1963, 16, 770.

[10] W.D. Carlson, in 'Carbonates, Mineralogy and Chemistry', Ed. R.J. Reeder, Mineralogical Society of America, 1983, p. 191.

[11] R.J.P. Williams, Philos. Trans. R. Soc. London, Ser. B 1984, 304, 411.

[12] S. Weiner, W. Traub, Philos. Trans. R. Soc. London Ser. B 1984, 304, 425.

[13] P. Westbroek, E.W. DeJong, P. Van der Wal, A.H. Borman, J.P.M. DeVrind, D. Kok, W.C. De Bruijn, S.B. Parker, Philos. Trans. R. Soc. London, Ser. B 1984, $304,435$.

[14] M. Maciejewski, A. Reller, Thermochim. Acta $1987,110,145$

[15] M. Maciejewski, A. Reller, Thermochim. Acta $1989,142,175$

[16] C. Padeste, Ph.D. thesis, University of Zürich, 1989.

[17] C. Padeste, A. Reller, H.R. Oswald, Mat. Res. Bull. 1990, 25, 1299.

[18] A. Reller, C. Padeste, P. Hug, Nature (London) $1987,329,527$

[19] R. Emmenegger, H.R. Oswald, A. Reller, Sol. Energy Mater., in press.

[20] R. Memming, Topics Curr. Chem. 1991,143,81.

[21] A. Henglein, Topics Curr. Chem. 1991, 143, 115.
Chimia 45 (1991) 266-268

(c) Schweiz. Chemiker-Verband; ISSN 0009-4293

\section{Self-replicating Reverse Micelles}

Pascale Angelica Bachmann'), Pier Luigi Luisi')*, and Jacques Lang²)

Abstract. Conditions are described, under which the hydrolysis of octyl octanoate (O-OA) takes place at the interface of reverse micelles formed by sodium octanoate (OA) in isooctane. Since the micelle-mediated hydrolysis affords fresh OA, which spontaneously assemble into new micelles, the reaction can be seen as a self-replicating process. The kinetics and the spectroscopy of this self-replication process are presented.

\section{Introduction}

Reverse micelles can be seen as small droplets of $\mathrm{H}_{2} \mathrm{O}$ (with a radius in the range of $10-100 \AA)$ which are stabilized in organic solvents by a layer of surfactant. Reverse micelles are usually monodisperse, and their physical properties depend primarily on the molar ratio of $\mathrm{H}_{2} \mathrm{O}$ to surfactant, usually defined as $w_{0}\left(w_{0}=\left[\mathrm{H}_{2} \mathrm{O}\right] /[\right.$ surfactant $\left.]\right)$ :e.g., the radius of the $\mathrm{H}_{2} \mathrm{O}$ pool depends almost linearly on $w_{0}[1-3]$. To an organic chemist, reverse micelles are also of interest as microreactors: a series of $\mathrm{H}_{2} \mathrm{O}$-soluble compounds can be solubilized in the $\mathrm{H}_{2} \mathrm{O}$ pool of the micelles, thus permitting reactions between hydrophilic compounds essentially in a bulk aprotic solvent [4][5].

Quite recently, a new type of a chemical reaction in reverse micelles has been proposed [6], one which brings to self-replication of the micelles themselves. The principle is the following: the reverse micelle hosts a reaction which yields the very surfactant which builds the micelle. The soproduced fresh surfactant accumulates at the micellar interface; however, the micelle cannot grow in size, since $\mathrm{H}_{2} \mathrm{O}$ is limiting. Actually, since $w_{0}$ decreases, the thermodynamic constraints impose formation of a

\footnotetext{
*Correspondence: Prof. P. L. Luisi

1) Institut für Polymere, ETH-Zentrum

Universitätstrasse 6, CH-8092 Zürich

2) Institut Charles Sadron (CRM-EAHP) CNRS

6 , rue Boussingault, F-67000 Strasbourg
} 
larger number of smaller micelles. Since this increase in number is due to a chemical reaction which takes place within the domain of parent micelles, it is appropriate to view the micelle population growth as a 'self-replication' process. A couple of other self-replicating systems have been proposed already in the chemical literature, based on the quite different principle of template reactions [7][8]. In our system, the emphasis is on the replication of geometrically closed structures.

Such a self-replicating micelle system has been presented in a preliminary communication without kinetic data and without discussing the ongoing spectroscopic events [6]. The aim of this paper is to provide this additional and still missing information and to further discuss the principle of self-replication in reverse micelles.

\section{Results and Discussion}

It may be worthwhile to recall that the system consists of an apolar solvent mixture, i.e. isooctane/octan-1-ol 9:1 (v/v), and that the reverse micelles are built by sodium octanoate (OA). Octan-1-ol (OL) is at the same time co-solvent and co-surfactant. $\mathrm{LiOH}$ in a concentration of $2.86 \mathrm{M}$ (chosen over $\mathrm{NaOH}$ for its greater solubility in reverse micelles) is confined in the $\mathrm{H}_{2} \mathrm{O}$ pool at $w_{\mathrm{o}}=9.2(23 \mathrm{~mm} \mathrm{LiOH}$ overall concentration), whereas excess of octyl octanoate $(\mathrm{O}-\mathrm{OA})$ is dissolved in the system, being localized mostly in the bulk solvent and partly at the micellar interface, where the hydrolysis reaction takes place. The resulting fresh $O A$ and $O L$ lead to new micelles.

A pictorial representation of the system is given in the Scheme, whereas the time progress of a typical reaction is illustrated in Fig. 1 .

The time progress of the reaction has been followed by Fourier transform IR spectroscopy. The principle of the method has already been described in another context [9] . As the ester is hydrolyzed, the intensity of the $\mathrm{C}=\mathrm{O}(s)$ band around 1744 $\mathrm{cm}^{-1}$ decreases, while at the same time the intensity of the $\mathrm{C}=\mathrm{O}(s)$ of the octanoate around $1570 \mathrm{~cm}^{-1}$ increases (Fig. IB). The formation of octan-1-ol during the reaction can be monitored in the $\mathrm{O}-\mathrm{H}(s)$ region of the IR spectrum, by looking at the increase in the intensity of the band which is centered around $3250 \mathrm{~cm}^{-1}$ (Fig. 1A). The kinetics of the reaction can be analyzed by following the decrease of the ester band at $1744 \mathrm{~cm}^{-1}$. For this spectroscopic characterization, we have first carried out a calibration at this wavenumber with known amounts of octyl octanoate in isooctane and then determined the extent of hydrolysis as a function of time.

As expected [10], the hydrolysis reaction is second order with respect to the ester, with an overall rate constant of $10^{-3} \mathrm{M}^{-1} \mathrm{~s}^{-1}$, as estimated from half-time determinations at different ester concentrations (data not

Scheme. Schematic Representation of the Micellar Reaction Leading to Self-replication of the Reverse Micelles

\section{Base-catalyzed ester modrolysis in reverse micelles}

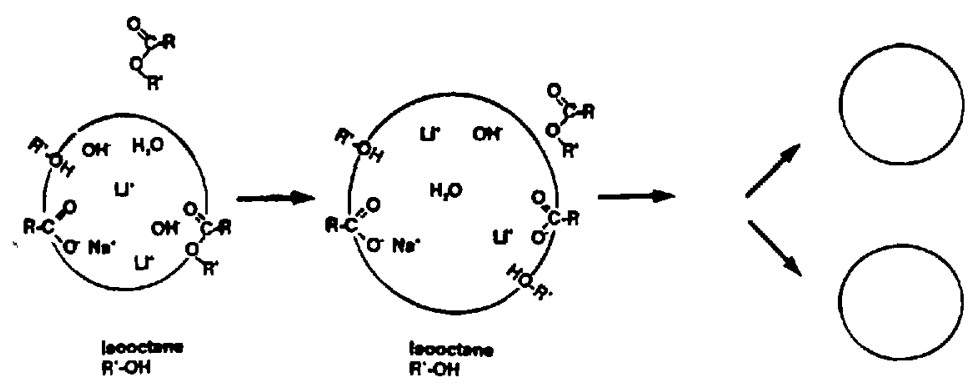

$\mathrm{CH}_{3}-\left(\mathrm{CH}_{2}\right)_{6}-\mathrm{CO}-\mathrm{O}-\left(\mathrm{CH}_{2}\right)+\mathrm{CH}_{3}+\mathrm{LOH}=\mathrm{CH}_{3}-\left(\mathrm{CH}_{2}\right)_{-}-\mathrm{COO} \mathrm{LI}+\mathrm{HO}-\left(\mathrm{CH}_{2}\right)_{-}-\mathrm{CH}_{3}$

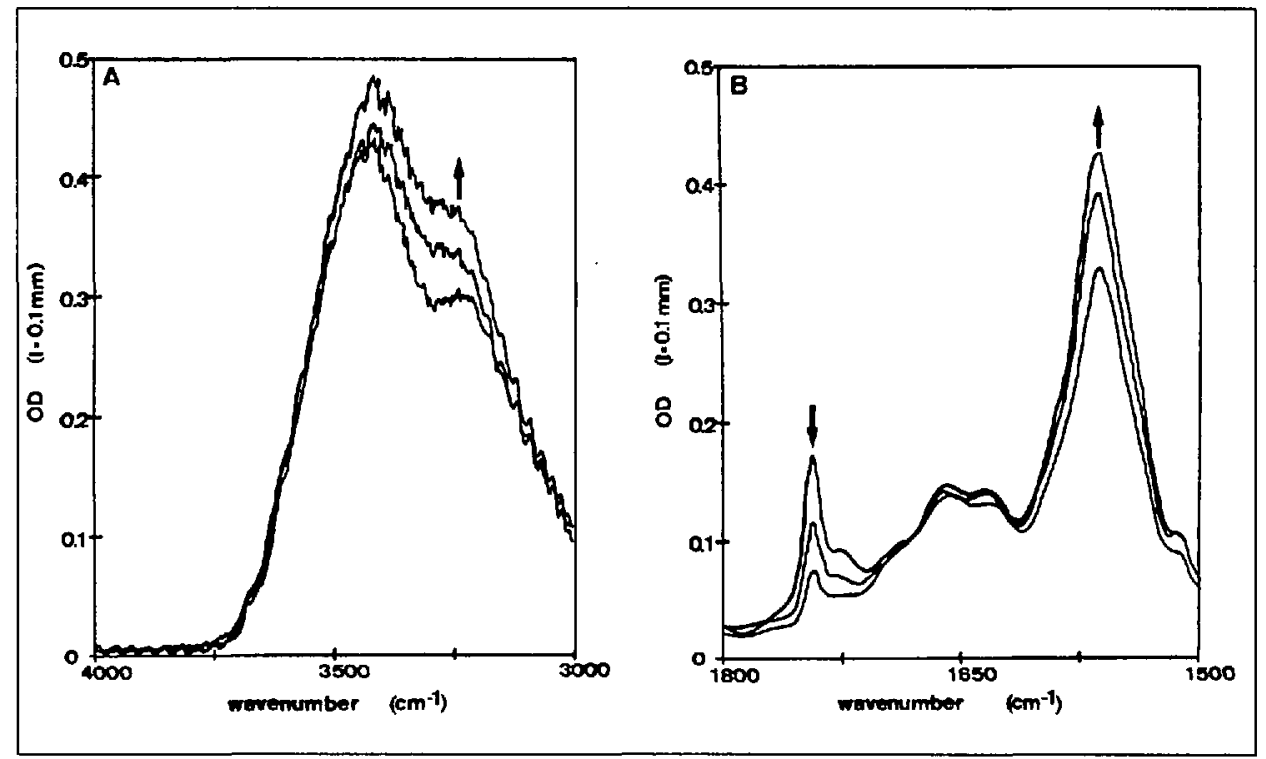

Fig. 1.LiOH-catalyzed hydrolysis of octyl octanoate in sodium octanoute reverse micelles: time course of the FTIR spectrum between 4000 and $3000 \mathrm{~cm}^{-1}$ (A) and between 1800 and $1500 \mathrm{~cm}^{-1}$ (B). Sodium octanoate (50 mM) in isooctane/octan- $1-$ ol $9: 1(v / v), w_{0} 9.2$, [octyl octanoate] $]_{0}=25 \mathrm{~mm},[\mathrm{LiOH}]=23 \mathrm{~mm}$, path length $=0.1 \mathrm{~mm} \mathrm{ZnS} \mathrm{cell.}$ Incubation times: 0,24 and $60 \mathrm{~h}$.

shown). The determined rate constant is comparable to the ester-hydrolysis rate constant obtained for $p$-nitrophenol octanoate in the reverse micellar system consisting of sodium octanoate, hexan-1-ol, and $\mathrm{H}_{2} \mathrm{O}[11]$.

The concentration change of the reverse micelles was measured by time-resolved fluorescence quenching [12][13]. According to this technique, the micelles contain a $\mathrm{H}_{2} \mathrm{O}$-soluble fluorescent probe - in our case 1-pyrenesulfonic acid- and a quencher - in our case NaI. Since the magnitude of the intramicellar quenching of the probe is proportional to the quencher concentration and inversely proportional to the micelle concentration, the method allows the determination of the concentration of the reverse micelles.

As shown in Fig. 2, the concentration of micelles increases from 1.9 to $3.0 \mathrm{~mm}$ while the concentration of octanoate increases from 50 to $68 \mathrm{~mm}$. Since the micelles become smaller, micellar radius and aggregation number of OA must also decrease. This two parameters can be calculated from the measured concentration of micelles by simple geometrical considerations [12], giving a decrease in the micellar radius from 12 to $10.3 \AA$ and a decrease in the aggregation number from 26.1 to 22.4 . The mean hydrodynamic radius of the reverse micelles has in addition been determined by quasi-elastic light scattering. From a cumulant analysis of the measured intensity autocorrelation function, the diffusion coefficient of the scattering species can be obtained. Knowing the diffusion coefficient, the hydrodynamic radius can be calculated by the Stokes-Einstein equation. The so determined hydrodynamic radius is $22.7 \AA$ at the beginning of the reaction, and $20.5 \AA$ at equilibrium (at the end of the self-replication process) in good agreement with the micellar radius determined by fluorescence quenching, taking $10.4 \AA$ for the length of an octanoate molecule. 


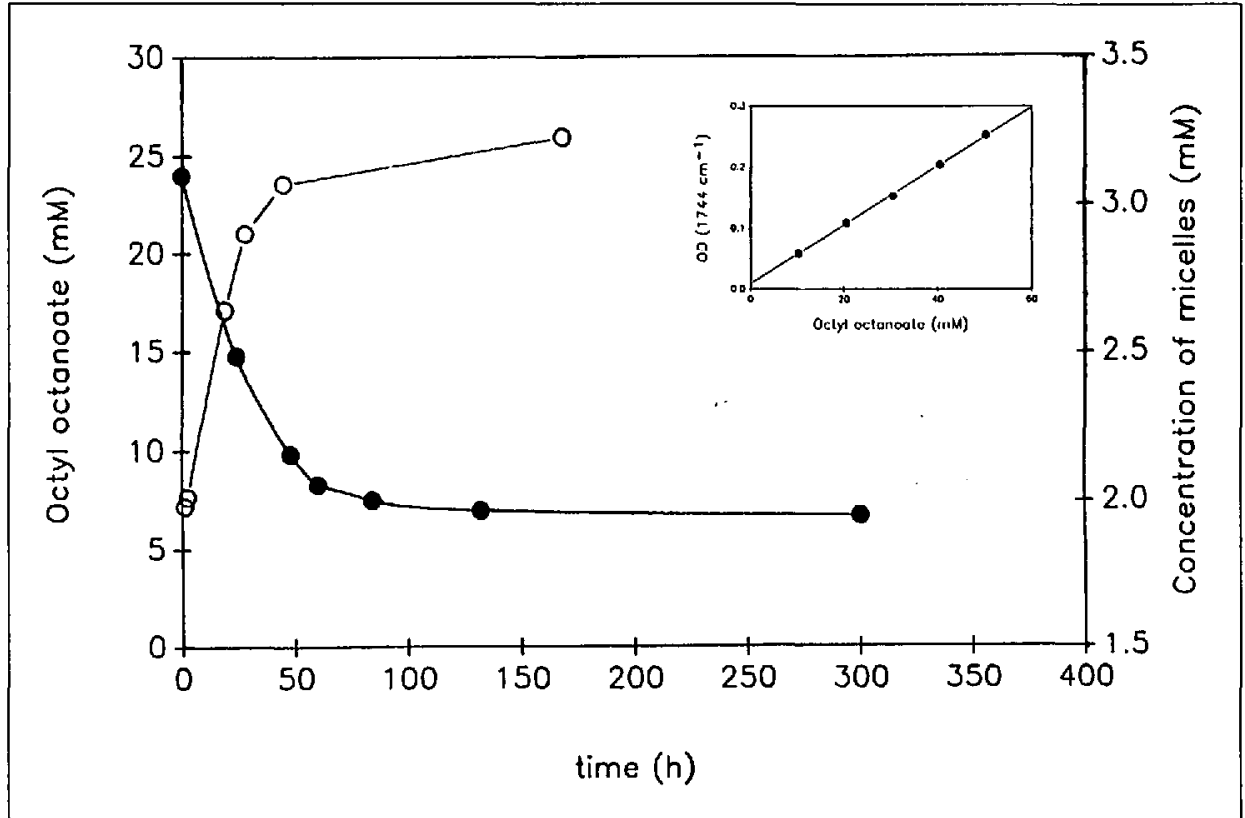

Fig. 2. Decrease of octyl octanoate concentration ( $\bullet$ ) and increase in the micellar concentration (O) with time for the LiOH-catalyzed hydrolysis reaction in sodium octanoute reverse micelles at $T=25^{\circ}$. Starting conditions are $50 \mathrm{~mm}$ sodium octanoate, $23 \mathrm{~mm} \mathrm{LiOH}, 24 \mathrm{~mm}$ octly octanoate and $w_{0}=9.2$. Insert: FTIR calibration of octyl octanoate. Concentration dependency of the $\mathrm{C}=\mathrm{O}(s)$ band intensity of octyl octanoate in isooctane/octan- $1-0 \mathrm{l} 9: 1$ (v/v). Pathlength: $0.1 \mathrm{~mm}, \mathrm{ZnS}$ cell

\section{Concluding Remarks}

There is a small shortcoming in the reaction illustrated here: since $w_{0}$ (and consequently the radius of the micelles) becomes smaller during replication, the self-replication is not completely warranted. In principle, one could try to avoid this by adding $\mathrm{H}_{2} \mathrm{O}$ so that $w_{0}$ remains constant during reaction, according to a method outlined in [15]. Another possibility is the use of coupled reactions, one of which producing $\mathrm{H}_{2} \mathrm{O}$ (e.g. the use of the enzyme tyrosinase which yields $\mathrm{H}_{2} \mathrm{O}$ upon oxidation of phenol). However, until now none of this was implemented experimentally.

Aside from these details, the reaction presented here, as simple as it is, represents a new class of micellar reactions, which most likely will be considerably developed in the near future. There are already reports indicating that the same self-replication principle can be extended to aqueous micelles [16] and even liposomes [17]. Thus, it is perhaps important to conclude with a couple of general observations.

Micelles and the other supramolecular surfactant complexes can be seen as geometrically closed structures which assemble spontaneously, and this combination of features makes them particularly suitable to model biological replication processes. Of course, given their chemical simplicity, supramolecular surfactant aggregates are very far from the complexity of a cell. On the other hand, precisely this simplicity may permit the understanding of some basic mechanistic steps.

Micellar self-replication offers another point of interest: the linkage with 'autopoiesis'. This notion, as developed by Maturana and Varela [18], tries to define the essential mechanistic aspects of the living; and essentially, an autopoietic system is one which is defined by a boundary, and in which domain a metabolic network of reactions takes place, which bring to the production of components, which then assemble spontaneously in the same bounded structure. As already emphasized [16][17], self-replicating micelles and liposomes offer in principle the challange of responding to the essential definition of living.

\section{Materials and Methods}

Reagents

1-Pyrenesulfonic acid sodium salt (PSA) was from molecular probes and octan-1-ol from Aldrich both of high purity grade. All other chemicals were of highest purity available from Fluka.

Octyl octanoate was synthesized by heating octanoic acid and octan-1-ol in concentrated $\mathrm{H}_{2} \mathrm{SO}_{4}$

\section{Methods}

Quasi-Elastic Light Scattering. Quasi-elastic light scaltering experiments were carried out with a Malvern $4700 \mathrm{PS} / \mathrm{MW}$ spectrometer and an Ar ion laser (coherent, Innova Model $200-10, \lambda_{0}=488 \mathrm{~nm}$ ). Hydrodynamic radii of the octanoate reverse micelles can be determined from a cumulant analysis of the intensity autocorrelation function with a reproducibility of $\pm 5 \%$.

Time-Resolved Fluorescence Quenching. The fluorescence decay curves of solubilized fluorescent probe and quencher (or probe alone) were obtained by the single-photon counting technique and analyzed according to a nonlinear weighted least-squares procedure [12].

For comparison with light scattering data, the hydrodynamic radius can be calculated as the sum of the $\mathrm{H}_{2} \mathrm{O}$ pool radius and the length of the extended surfactant molecule, which is $10.4 \AA$ for octanoate [ 14].

FTIR Spectroscopy. All Fourier transform IR spectra were recorded on a Nicolet $5 S X C$ FTIR spectrometer, using a $\mathrm{ZnS}$ cell from Textronica $A G$ with a fixed pathlength of $0.1 \mathrm{~mm}$. 36 scans were taken of each sample at a resolution of $4 \mathrm{~cm}^{-1}$.
Preparation of the Reaction Mixture and Quantification of the Reaction

An appropriate amount of $2.86 \mathrm{~m} \mathrm{LiOH}$ was added by a microsyringe (typically $40 \mu \mathrm{l}$ for $5 \mathrm{ml}$ of reaction soln.) to 50 mm sodium octanoate in isooctane/octan- Iol $9: 1\left(1 / v^{\prime}\right)$ to give the desired $w_{0}(9.2)$. The reagents were solubilized by vortexing and sonification, until a clear soln. was obtained. The reaction was started by adding octyl octanoate $(25 \mathrm{~mm})$ by a microsyringe. The mixture was kept at r.t. without stirring and samples were withdrawn at a desired time and analyzed by FTIR spectroscopy.

We like to thank Dr. P. Walde for helpful discussions

Received: May 17, 1991

[1] P.L. Luisi, M. Giomini, M.P. Pileni, B.H. Robinson, Biochim. Biophys. Acta 1988, 947, 209.

[2] J.D. Nicholson, J.H.R. Clarke, in 'Surfactants in Solution', Eds. K.L. Mittal and B. Lindman, Plenum Press, New York-London, 1984, Vol. 3, p. 1663.

[3] P.D.I. Flechter, B.H. Robinson, Ber. Bunsenges. Phys. Chem. 1981, 85, 863.

14] J.H. Fendler, E.J. Fendler, R.T. Medary, V.A. Woods, J. Am. Chem. Soc. 1972, 94, 7288.

[5] F.M. Menger, A.C. Vitale, J. Am. Chem. Soc. 1973, 95,4931 .

[6] P.A. Bachmann, P.Walde, P.L. Luisi, J. Lang, $J$. Am. Chem. Soc. 1990, 112, 8200 .

[7] G.Von Kiedrowski,Angew. Chem. 1986, 10,932.

[8] T. Tjivikua, P. Ballester, J. Jr. Rebek, J. Am. Chem. Soc. 1990, 1/2, 1249

[9] P. Walde, P.L. Luisi, Biochemistry 1989, 28, 3353.

[10] P.W. Atkins, in 'Physikalische Chemie', VCH Verlagsgesellschaft, Weinheim, 1987, p. 713.

[11] F. Hirotada, K. Thoru, N. Hiroyasu, Bull. Chem. Soc. Jpn. 1979, 52, 1978.

[12] J. Lang, A. Jada, A. Malliaris, J. Phys. Chem. $1988,92,1946$.

[13] A. Verbeeck, F.C. De Schryver, Langmuir 1987. 3, 494.

[14] D.M. Small, in 'Handbook of Lipid Research', Plenum Press, New York, 1986, Vol. 4, p. 67.

[15] P.L. Luisi, F. Varela, Origins Life Evol. Biosphere 1989. 19,633.

[16] P.A. Bachmann, P. Walde, P.L. Luisi, J. Lang, J. Am. Chem. Soc. 1991, in press.

[17] P.Schmidli, P. Schurtenberger, P.L. Luisi,J.Am. Chem. Soc. 1991, in press.

[18] F.J. Varela, H.R. Maturana, R. Uribe, BioSystems $1974,5,187$. 